\title{
COVID-19 and the World Congress on Controversies in Neurology
}

\author{
An Expert Interview with Amos D Korczyn \\ Department of Neurology, Tel Aviv University, Tel Aviv, Israel
}

DOI: https://doi.org/10.17925/ENR.2020.15.1.9

\begin{abstract}
Amos D Korczyn
Professor Amos Korczyn graduated with his medical doctorate from the Hebrew University-Hadassah Medical School in Jerusalem in 1966, where he also received an MSc degree in pharmacology (cum laude) in 1966. He trained in neurology at Beilinson Hospital, Israel, and at what is now the National Hospital for Neurology and Neurosurgery, Queen Square, London. He was the chairman of the Department of Neurology at the Tel-Aviv Medical Center from 1981 to 2002, and the incumbent of the Sieratzki Chair of Neurology at Tel-Aviv University, 1995-2010. Professor Korczyn has a particular interest in neurodegenerative diseases. He has authored or co-authored over 700 articles in peer-reviewed journals, as well as many book chapters. He has edited several books and special issues in journals, and is the regional editor of the Journal of Alzheimer's Disease. He is or has been an editorial board member of 20 international journals. He has organized several neurological conferences, mainly in the field of dementia, Parkinson's disease and other degenerative brain disorders, as well as CONy - the International Congress on Controversies in Neurology, and has organized the Mental Dysfunction in Parkinson's Disease congresses since 1993 and the Vascular Dementia congresses since 1999. Professor Korczyn has also served on advisory boards in several drug discovery programmes. Professor Korczyn is the chairman of the scientific medical board of the Israeli Alzheimer's Disease Association, member of the medical and scientific advisory panel of Alzheimer Disease International, and has been the chairman of the World Federation of Neurology's research committee for clinical neuropharmacology. He is also an honorary member of the neurological societies of Israel, Serbia, Poland, Russia and Romania, and received a doctorate honoris causa from the University of Medicine and Pharmacy, Cluj-Napoca, Romania in 2020.
\end{abstract}

\section{Keywords}

World Congress on Controversies in Neurology (CONy), COVID-19

Disclosure: Amos D Korczyn is the founder of the World Congress on Controversies in Neurology (CONy).

Acknowledgement: Medical writing assistance was provided by Katrina Mountfort of Touch Medical Media and supported by Touch Medical Media.

Review Process: This is an expert interview and, as such, has not undergone the journal's standard peer-review process.

Compliance with Ethics: This is an expert interview and does not report on new clinical data, or any studies with human or animal subjects performed by the author.

Authorship: The named author meets the International Committee of Medical Journal Editors (ICMJE) criteria for authorship of this manuscript, takes responsibility for the integrity of the work as a whole, and has given final approval to the version to be published.

Access: This article is freely accessible at touchNEUROLOGY.com @ Touch Medical Media 2020

Received: 28 August 2020

Published Online: 28 September 2020

Citation: European Neurological Review. 2020;15(1):9-10

Corresponding Author: Amos D Korczyn,

Tel Aviv University, Ramat Aviv 69978, Israel.

E:amoskor@tauex.tau.ac.il

Support: No funding was received in

the publication of this article.
$\mathrm{T}$ he World Congress on Controversies in Neurology (CONy) provides a platform for international experts to discuss and compare experiences. Its debate-style structure bridges the gap between the latest scientific advances and their dissemination and use. The congress has become a major annual event for members of the neurological community. As a result of the COVID-19 pandemic, the 14th CONy will be a fully online virtual experience that will take place from 29 October to 1 November, 2020. Further details can be found at http://cony.comtecmed.com/

In this expert interview, Professor Korczyn presents some highlights of the upcoming conference, as well as discussing the neurological implications of COVID-19.

\section{Q. What do you expect to be the highlights of the 14th World Congress on Controversies in Neurology, now being held virtually (CONy 2020)?}

This year CONy will be different from the past as it will be an online meeting. This will make it easier for everyone to attend, but they will miss meeting each other and having face-to-face discussions. The programme will be based on debates on current issues in neurology, including Parkinson's disease (PD), dementia, epilepsy, multiple sclerosis, headache, stroke and much more. There will be at least eight different debates in each topic. We are going to begin with my debate with John Hardy from University College, London about the issue of genetics of Alzheimer's disease (AD). Genome-wide association studies (GWAS), have found many different variants associated with AD. The debate focuses on whether understanding these variants is important to the treatment of AD. Professor Hardy argues that GWAS is likely to contribute significantly to AD patient care; I am taking the opposing view. This is an example of the type of debate that will take place, with discussions afterwards and voting before and after.

There is also a dementia satellite together with the Alzheimer's Association that will discuss the value of animal models of $A D$ in planning treatment, and whether non-pharmacological interventions such as exercise, brain training and dieting are important quantitatively, i.e., if we invest time and money in these interventions, will it delay the onset of dementia or prevent it altogether? If they only delay dementia onset, then by how much? Weeks? Months? Decades? These are important issues that we still know little about and it is important to investigate. We will also discuss new treatment targets such as apolipoprotein $\mathrm{E}$, risk factors, and the disappointments of expensive studies targeting beta-amyloid and tau. 
There will also be neuroimmunology debates that will discuss whether narcolepsy is an autoimmune disorder, and if so, should it be treated as such? There will also be a presentation about paediatric acute neuropsychiatric syndromes such as paediatric autoimmune neuropsychiatric disorders (PANDAS), their association with streptococcal infection and whether they should be treated as an autoimmune disease.

There will be several debates on PD, including the dilemma of how soon we can employ non-dopaminergic treatment, and surrounding the late stages of PD when psychotic features appear. Should we treat psychosis or wait for other symptoms to appear? There will be debates on amyotrophic lateral sclerosis (ALS), including whether mouse models have helped or hindered the study of ALS and who should set the agenda for therapeutic trials in ALS: investigators or patients? Surrounding the topic of headache disorders, there will be debates on calcitonin gene-related peptide (CGRP) monoclonal antibodies, vestibular migraine and the future of telemedicine in headache treatment. Debates on epilepsy will consider when the best time to initiate combination antiepileptic drugs (AED) is, after the failure of a single AED or should another monotherapy be implemented first, and many more.

I hope everyone will enjoy the debates and participate by asking questions and voting. We hope to return to the normal format in March 2021, with a meeting planned in Dubrovnik, Croatia.

\section{Q. Could you give us an overview of the neurological implications of COVID-19?}

The common symptoms of COVID-19 (fever, fatigue, cough, shortness of breath and loss of smell) are well known. People also complain about a loss of taste, but this is most likely related to the loss of smell. Neurological complications are uncommon except in very advanced cases, and tend to be non-specific, like delirium. ${ }^{1}$ Young people who have been hospitalised with COVID-19 appear to have an increased risk of associated stroke, but this is quite rare. ${ }^{2}$ Other rare manifestations have been reported, such as epileptic seizures, and polyneuropathy, including Guillain-Barré syndrome and myopathy. ${ }^{1}$ However, we do not know whether a causal relationship exists between COVID-19 and these complications.

We must remember that, as well as older people and those with comorbidities, prisoners, refugees and of course medical staff and carers are also more vulnerable. We should also remember that in the long term, COVID-19 will disappear. At present there are, in the USA, about a million patients with PD and twice as many with COVID-19. In 2030, we will have more patients with $\mathrm{PD}$, perhaps 1.2 million, but the number of patients with COVID-19 is likely to be zero.

We know how to prevent COVID-19: hygiene measures and physical isolation. Vitamin D is also interesting as a preventative strategy, as vitamin D deficiency may be implicated in the COVID-19 pathogenesis. ${ }^{3}$ We should pay more attention to the future impact of the current situation - people who are confined to their homes tend to remain out of touch with other people, which leads to increased stress, especially in people with limited comprehension, such as those with mild cognitive impairment. This is important because increased stress may cause a release of cytokines. Cytokine release syndrome, or so-called "cytokine storm", leading to inflammation, is known to be an important issue in COVID-19. Sometimes patients have specific problems, for example in patients with PD taking dopaminergic drugs, the development of impulse control disorder. In older patients with PD who develop COVID-19, we have to consider the consequences of them being admitted into hospital. There, patients will be cared for by staff wearing "astronaut" gowns and masks and being unable to see their loved ones. Patients may need to be intubated, sedated, and if they survive, there is a risk of critical illness myopathy, and even post-traumatic stress disorder. We need to consider whether the consequences of hospitalisation will benefit the patient.

On the positive side, the age of telemedicine allows us to communicate with our patients and, to some degree, reduce their isolation and address their fear and stress. We cannot perform full physical examinations, but we can communicate remotely via platforms such as Zoom, which we certainly should do. $\square$ 